\title{
Atypical Symptoms in Patients With Gastroesophageal Reflux Disease
}

\author{
Chih-Hsun Yi, Tso-Tsai Liu and Chien-Lin Chen ${ }^{*}$ \\ Department of Medicine, Buddhist Tzu Chi General Hospital and Tzu Chi University, Hualien, Taiwan
}

\section{Background/Aims}

Atypical symptoms are common in gastroesophageal reflux disease (GERD). Patients with non-erosive reflux disease (NERD) and erosive reflux disease (ERD) exhibit different clinical characteristics and responses to acid suppression treatment. We aimed to compare atypical characteristics in patients with NERD and ERD. We also investigated the presence of histological esophagitis in patients with NERD and ERD.

\section{Methods}

Eligible patients completed a questionnaire regarding reflux symptoms and concomitant atypical symptoms. Endoscopic biopsies with histological examination were performed.

\section{Results}

Of the 210 patients with GERD, 90 patients with ERD and 120 patients with NERD were studied. ERD patients were characterized by higher prevalence of hiatal hernia $(P=0.001)$ and smoking $(P=0.047)$. The prevalence of GERD was greater in the age group between 41 and 60 years regardless of endoscopic finding. There was no difference in the prevalence of atypical symptoms or histological esophagitis between NERD and ERD. In all subjects, heartburn was associated with dysphagia ( $r$ $=0.16, P=0.01)$, dyspepsia $(r=0.22, P=0.008)$ and hiccup $(r=0.19, P=0.003)$, whereas acid regurgitation was associated with dyspepsia $(r=0.21, P=0.014)$, belching $(r=0.15, P=0.018)$ and hiccup $(r=0.19, P=0.002)$.

\section{Conclusions}

Atypical symptoms did not correlate with the presence of histological esophagitis. Atypical symptoms were equally prevalent in patients with NERD and ERD. The existence of atypical symptoms appears to be associated with the presence of typical reflux symptoms irrespective of endoscopic and histological reflux esophagitis.

(J Neurogastroenterol Motil 2012;18:278-283)

\section{Key Words}

Atypical symptoms; Gastroesophageal reflux; Prevalence

Received: November 5, 2011 Revised: February 2, 2012 Accepted: February 10, 2012

(c) This is an Open Access article distributed under the terms of the Creative Commons Attribution Non-Commercial License (http://creativecommons. org/licenses/by-nc/3.0) which permits unrestricted non-commercial use, distribution, and reproduction in any medium, provided the original work is properly cited.

*Correspondence: Chien-Lin Chen, MD, PhD

Department of Medicine, Buddhist Tzu Chi Hospital, 707, Section 3, Chung-Yang Road, Hualien 970, Taiwan

Tel: +886-3-856-1825, Fax: +886-3-857-7161, E-mail: harry.clchen@msa.hinet.net

Financial support: This study was supported by a grant (TCRD 98-24) from Buddhist Tzu-Chi General Hospital, Taiwan.

Conflicts of interest: None. 


\section{Introduction}

Gastroesophageal reflux disease (GERD) is common and occurs when reflux of stomach contents into the esophagus causes troublesome symptoms and/or complications. ${ }^{1}$ The most commonly recognized symptoms of GERD are heartburn and/or regurgitation, although GERD is often associated with other manifestations such as globus sensation, non-obstructive dysphagia, chest pain, chronic cough, hiccup, dyspepsia or belching. ${ }^{2-4}$ Although evidence-based consensus includes cough, laryngitis, asthma and dental erosions as atypical presentations, ${ }^{1}$ other atypical symptoms are also common with significant impact in GERD patients. ${ }^{2}$ Due to the fact that most patients with GERD have no erosions on endoscopy, GERD has been further classified into erosive reflux disease (ERD) and non-erosive reflux disease (NERD). ${ }^{1,5}$ It is evident that NERD is not a milder form of GERD, since similar impact on quality of life has been demonstrated irrespective of the presence of mucosal injury. ${ }^{6,7}$

It has been reported that atypical manifestations are slightly greater in patients with ERD than NERD in a European multicenter study. ${ }^{6}$ A population-based study in Korean has recently revealed that typical reflux symptoms are significantly associated with atypical symptoms. ${ }^{2}$ Of interest is that increased frequency of typical GERD symptoms was found more in patients with atypical symptoms than those without any atypical symptoms. ${ }^{2}$ Further study has indicated that NERD is characterized by concomitant presence of functional gastrointestinal disorders in a group of Chinese patients. ${ }^{4}$ Given the fact that racial and geographic differences may influence the presence of GERD and its related syndromes, ${ }^{8}$ the aim of this study was to investigate clinical characteristics and concomitant atypical manifestations in patients with GERD, and to compare their occurrence between patients with ERD and NERD. Secondly, we determined the presence of histological esophagitis in patients with GERD, and correlated histological esophagitis with clinical manifestations. The association between clinical characteristics and atypical symptoms was also determined.

\section{Materials and Methods}

\section{Subjects}

Between January 2009 and July 2010, consecutive patients with predominant typical symptoms (ie, heartburn and/or acid re- gurgitation) of GERD occurring at least 3 times weekly were enrolled in the study in GI clinic of Buddhist Tzu Chi General Hospital, Taiwan. The study excluded patients with a history of previous gastrointestinal surgery, esophageal stricture, psychiatric disorders, malignancy or other major illnesses. Subjects were excluded if they had significant illness that may limit the ability to complete the questionnaire. All patients were responsive to prior therapy with proton pump inhibitor or histamine 2 receptor antagonist to confirm that the reflux symptoms were acid-related. The study protocol was approved by Ethics Committee of Tzu Chi Medical Center (Taiwan). The informed written consent was obtained from each subject.

\section{Endoscopy}

The extent of mucosal damage was noted and assessed using the Los Angeles grading system. ${ }^{9}$ ERD was defined by the presence of endoscopically detectable mucosal breaks (erosions or ulcer), while NERD was diagnosed in cases where endoscopically detectable mucosal lesions were absent together with the presence of typical reflux symptoms responsive to acid inhibitory drugs. We excluded minimal change esophagitis which was determined by the appearances on distal end of esophageal mucosa (whitish change and/or erythema and/or erosion that is not regarded as mucosal break). ${ }^{10}$ Hiatal hernia was considered present if gastric folds were assessed as extending $\geq 2 \mathrm{~cm}$ above the diaphragmatic hiatus during quiet respiration. ${ }^{11}$ During the endoscopic examination, 2 biopsies of the distal esophagus $(1 \mathrm{~cm}$ above the squamo-columnar junction) as well as the proximal esophagus (20 cm from the incisor) were taken in order to achieve sample consistency in all subjects. Esophagitis was identified if there was (1) basal cell hyperplasia $>15 \%$ of the total epithelium, (2) increased papillary length $>66 \%$ of the squamous epithelium and (3) infiltration by polymorphonuclear leukocytes or eosinophils, or both. ${ }^{12}$ The diagnosis of histological esophagitis required at least 2 of the above findings. Diagnosis of Helicobacter pylori infection was confirmed if both biopsy urease test and histology results were positive.

\section{Assessment of Symptoms}

Before the EGD study, patients' symptoms were recorded by a face-to-face interviewer with the help of a questionnaire that was designed to assess the type and frequency of symptoms. All patients underwent a structured interview including a careful medical history, current medication, tobacco use and alcohol consumption. The following symptoms were considered, including 
heartburn, acid regurgitation, non-cardiac chest pain, dysphagia, globus and cough. In addition, concomitant dyspepsia was diagnosed according to a previous publication. ${ }^{13}$ Patients with 1 or more of these symptoms (postprandial fullness, early satiation or epigastric pain) are referred to as patients with dyspepsia. Other symptoms such as hiccup and belching were also recorded. Symptom frequency was determined as the following scale: 1 , less than once a month; 2 , about once a month; 3 , about once a week; 4 , twice to 4 times a week; and 5, daily. Presence of symptoms was considered if above-mentioned symptoms occurred once a week or more. The questionnaire for symptom assessment has been used and validated in our previous studies. ${ }^{14-16}$

\section{Statistical Methods}

The $\chi^{2}$ test (with Fisher's exact or Yate's corrections, as appropriate) was used to determine whether observed differences in proportions between study groups were statistically significant. Continuous data were expressed as mean \pm SEM. Differences in continuous data were analyzed by Student's $t$ test or non-parametric tests when appropriate. The correlations between atypical and reflux symptoms were analyzed by Kendall's rank correlation. A $P$-value of $<0.05$ was accepted as indicating statistical significance. Statistical analyses were conducted with SPSS for Windows 11.0 (SPSS Inc., Chicago, IL, USA).

\section{Results}

Two hundred and ten patients with typical symptoms of GERD met the enrollment criteria and entered the study. Based on the findings of upper endoscopy, 90 patients (47\%) had ERD,

Table 1. Comparison of Clinical Features Between Erosive Reflux Disease and Non-erosive Reflux Disease Patients

\begin{tabular}{lccc}
\hline \multicolumn{1}{c}{ GERD category } & $\begin{array}{c}\text { ERD } \\
(\mathrm{n}=90)\end{array}$ & $\begin{array}{c}\text { NERD } \\
(\mathrm{n}=120)\end{array}$ & $P$-value \\
\hline Age $(\mathrm{yr})$ & $47.0 \pm 1.6$ & $45.1 \pm 1.2$ & 0.340 \\
Sex $(\mathrm{man})(\mathrm{n}[\%])$ & $36(40)$ & $39(32.5)$ & 0.160 \\
BMI $\left(\mathrm{kg} / \mathrm{m}^{2}\right)$ & $27 \pm 2.8$ & $26 \pm 3.5$ & 0.200 \\
Current drinker (n [\%]) & $14(15.6)$ & $16(13.3)$ & 0.160 \\
Current smoker (n [\%]) & $26(28.9)$ & $21(17.5)$ & 0.047 \\
Duration of GERD (mo) & $17 \pm 4$ & $13 \pm 2$ & 0.350 \\
Hiatal hernia (n [\%]) & $14(15.6)$ & $20(16.7)$ & 0.001 \\
H. pylori status (n [\%]) & $26(28.9)$ & $27(22.5)$ & 0.170 \\
\hline
\end{tabular}

GERD, gastroesophageal reflux disease; ERD, erosive reflux disease; NERD, non-erosive reflux disease; BMI, body mass index; H. pylori, Helicobacter pylori. Data are expressed as mean \pm SEM or percentage. and 120 patients (53\%) had NERD (Table 1). Among patients with ERD, 72 (80\%) had grade A disease, 12 (13\%) had grade B disease, $4(5 \%)$ had grade $\mathrm{C}$ disease, and $2(2 \%)$ had grade D disease. Both groups of patients had comparable age, gender, body mass index, disease duration and $H$. pylori infection. Hiatal hernia was more prevalent in patients with ERD (Table 1). There was no difference in alcohol use; however, smoking was found more prevalent in patients with ERD. Figure 1 shows the sex and age specific frequencies and endoscopic diagnosis for all subjects. No significant differences in age trends between genders were found for GERD or its endoscopic diagnosis; however, the prevalence appeared to be more prominent in the age group between 41 and 60 years old for GERD or any endoscopic diagnosis (Fig. 1).

The frequencies of atypical symptoms in all subjects are shown in Table 2 . There were no statistically significant differences for the presence of chest pain, dysphagia, globus or cough between ERD and NERD patients (Fig. 2A). The frequencies of other symptoms (dyspepsia, belching and hiccup) were also similar between 2 groups of patients (Fig. 2B). The frequencies of atypical symptoms in all subjects are shown in Table 2. Of interest is the fact that dysphagia correlated with the symptom of heartburn; however, acid regurgitation did not. There was a small, but significant correlation with both heartburn and acid regurgitation and symptoms of dyspepsia and hiccup (Table 2).

Histological esophagitis in the proximal esophagus was detected in $45.9 \%$ of patients, whereas $51.9 \%$ of patients had histological esophagitis in distal esophagus. No significant difference was observed in the presence of histological esophagitis between patients with ERD and NERD for either proximal or distal

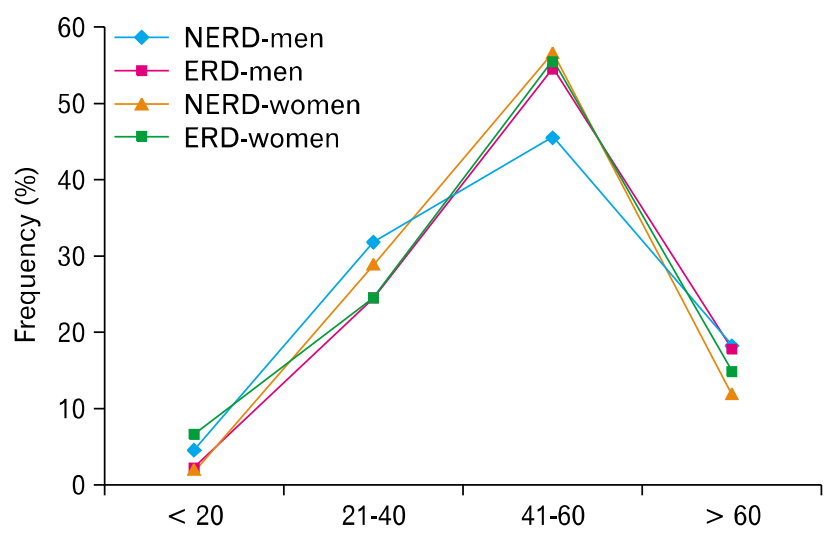

Figure 1. Age- and sex-specific frequencies of gastroesophageal reflux disease and its endoscopic diagnosis in all subjects. NERD, non-erosive reflux disease; ERD, erosive reflux disease. 

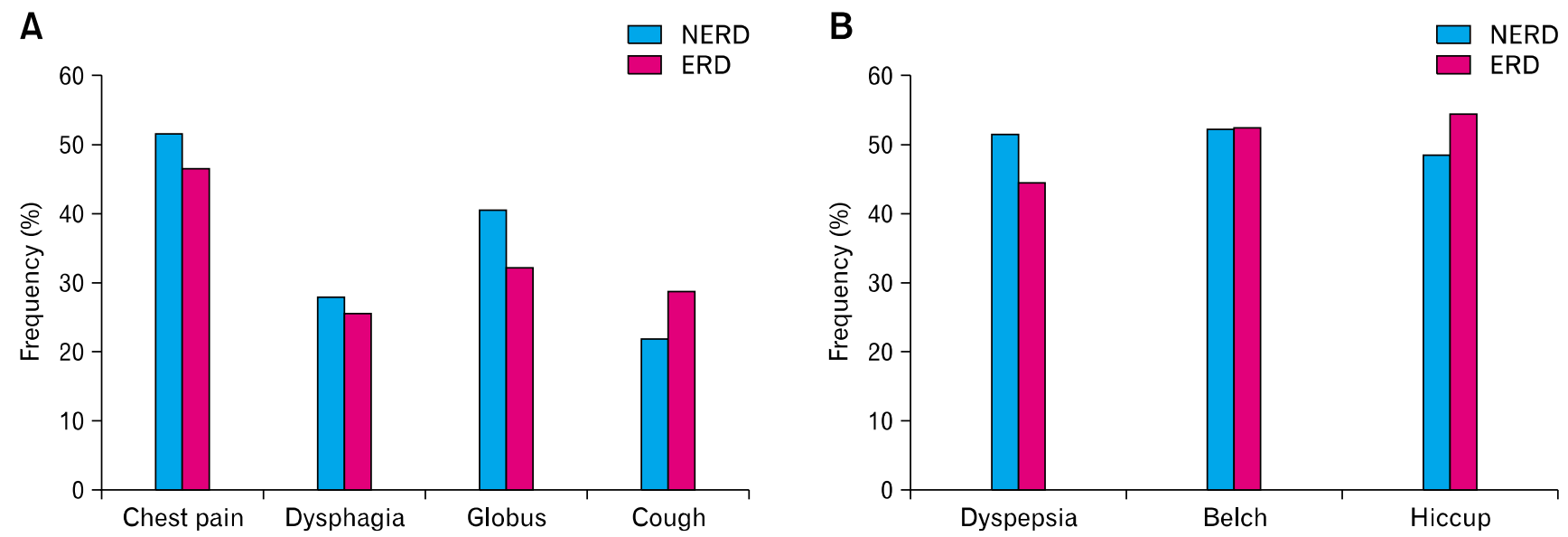

Figure 2. The frequencies of atypical symptoms in all subjects. (A) No significant difference was observed for the presence of chest pain, dysphagia, globus or cough between erosive reflux disease (ERD) and non-erosive reflux disease (NERD) patients. (B) The frequencies of other symptoms (dyspepsia, belching and hiccup) were similar between ERD and NERD patients.

Table 2. Frequency of Atypical Symptoms and the Correlation With Gastroesophageal Reflux Disease Symptoms

\begin{tabular}{|c|c|c|c|c|c|}
\hline & \multirow[t]{2}{*}{ Number (\%) } & \multicolumn{2}{|c|}{ Heartburn } & \multicolumn{2}{|c|}{$\begin{array}{c}\text { Acid } \\
\text { regurgitation }\end{array}$} \\
\hline & & $\mathrm{r}$ & $P$-value & $\mathrm{r}$ & $P$-value \\
\hline Dysphagia & $58(27.6)$ & 0.16 & 0.010 & 0.02 & 0.810 \\
\hline Chest pain & $106(50.5)$ & 0.08 & 0.210 & 0.01 & 0.860 \\
\hline Globus & 77 (36.7) & 0.01 & 0.990 & 0.08 & 0.190 \\
\hline Cough & $28(22.1)$ & 0.12 & 0.100 & 0.07 & 0.290 \\
\hline Dyspepia & $111(52.9)$ & 0.22 & 0.008 & 0.21 & 0.014 \\
\hline Belch & $112(54.6)$ & 0.04 & 0.520 & 0.15 & 0.018 \\
\hline Hiccup & $113(55.1)$ & 0.19 & 0.003 & 0.19 & 0.002 \\
\hline
\end{tabular}

esophagus (Fig. 3). In addition, the presence of histological esophagitis did not correlate with any of atypical symptoms.

\section{Discussion}

Despite predominant symptoms traditionally recognized as heartburn and regurgitation, GERD can be characterized by different clinical manifestations such as atypical symptoms. ${ }^{1,5,6,17}$ Our study has shown, in addition to heartburn and/or acid regurgitation, atypical symptoms to be present in a significant proportion of patients undergoing upper endoscopy. We found a similar prevalence of atypical manifestations in patients with NERD and ERD, although hiatal hernia and smoking occurred more frequently in patients with ERD than NERD. In addition, analysis of symptom association has demonstrated: (1) heartburn

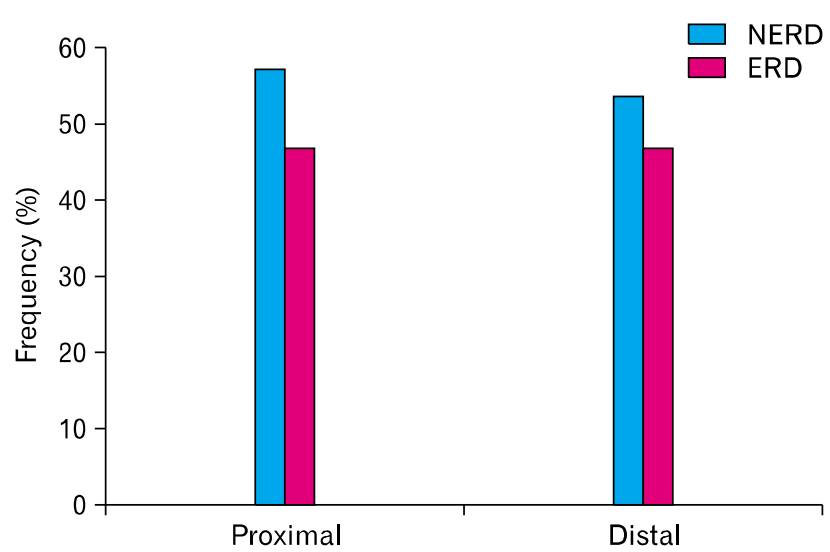

Figure 3. Histological esophagitis in proximal and distal esophagus. Histological esophagitis occurred similarly between patients with erosive reflux disease and non-erosive reflux disease for proximal or distal esophagus. NERD, non-erosive reflux disease; ERD, erosive reflux disease.

correlated with dysphagia, dyspepsia and hiccup; and (2) acid regurgitation correlated with dyspepsia, belching and hiccup.

In this study, we observed $53 \%$ of our patients with typical reflux symptoms exhibited normal esophageal mucosa during endoscopy. Our findings are in agreement with a recent report that suggests the prevalence of NERD is between $50 \%$ and $70 \%$ of patients with GERD related symptoms. ${ }^{18}$ Despite no difference in the prevalence among different age groups, there was a tendency with increased prevalence in the age group between 41 and 60 years old regardless of NERD or ERD. Our data are in line with earlier studies which showed the prevalence of GERD 
to significantly increase after the age of 40 years. ${ }^{18,19}$

Our findings corroborate previous results from epidemiological and therapeutic investigations that have demonstrated a strong relation between GERD and extra-esophageal manifestations. ${ }^{6}$ Increased prevalence of cough $(22.1 \%)$ or chest pain $(50.5 \%)$ was present in our patients, which appears to be similar between NERD and ERD patients, although an earlier study has shown a marginal difference with such symptoms detected more in patients with ERD than NERD. ${ }^{6}$ Similar finding has been reported to be greater in patients with ERD than NERD. ${ }^{20}$ Although the atypical symptoms such as chronic cough or chest pain are relatively common and thus likely to coexist with GERD, we did not observe any significant association between these symptoms and typical symptoms of GERD. It has been indicated that the strength of the association between these symptoms and GERD remains controversial. $^{21}$

We observed about half of our patients had concomitant dyspepsia with similar prevalence between NERD and ERD patients. The findings are in agreement with a previous work, which has demonstrated functional gastrointestinal disorders are particularly common in patients with GERD. ${ }^{22}$ In contrast to our findings, a recent study using Rome II criteria has revealed that functional dyspepsia are far more common in patients with NERD (64\%) than ERD (42\%), although the authors did not identify any difference in subtype of functional dyspepsia in their patient groups. ${ }^{4}$ Taking together with these findings, the discrepancy may be explained by the difference in the population studied and type of questionnaire used etc. It has been suggested that ethnic and cultural differences might influence the presence of GERD as well as relevant symptoms. ${ }^{8}$ The difference in the questionnaire used may also impact the findings in clinical observation of functional gastrointestinal disorder. ${ }^{23}$ Of interest is that we found that dyspepsia was significantly associated with heartburn and acid regurgitation. This might further support an earlier notion and indicate a potential link between function dyspepsia and GERD regardless of endoscopic changes. ${ }^{4}$

Belching is frequently reported in patients with functional disorder or GERD. ${ }^{24}$ Although the relationship of belching and GERD has not been well characterized, a previous work has demonstrated that belching correlates well with acid reflux more often in GERD patients than dyspeptic subjects. ${ }^{25}$ Therefore, it is suggested that belching is a manifestation of GERD and that GERD should be considered in patients with significant belching. ${ }^{25}$ In our study, we also observed a significant proportion of our patients with belching or hiccup. Furthermore, it was shown that belching and/or hiccup correlated well with the presence of heartburn and regurgitation, supporting the notion that belching is an important manifestation of GERD. ${ }^{25}$

Ismail-Beigi et $\mathrm{al}^{26}$ have suggested that acid reflux induces characteristic changes in the esophageal mucosa, ie, basal cell hyperplasia and papillary elongation, and that histology is helpful for the diagnosis of GERD. ${ }^{26}$ Further study has demonstrated typical histological changes could be present in patients with NERD. ${ }^{27}$ In the present study, we observed that histological esophagitis was found in nearly half of the patients for proximal and distal esophagus, and occurred equally in patients with ERD and NERD. Our finding is supported by a recent report that indicated microscopic esophageal lesions could occur in a majority of GERD patients without visual lesions at conventional endoscopy, and such histological features were associated with abnormal acid exposure and responded to acid-suppressive therapy. ${ }^{28,29}$ It is suggested that the presence of proximal histological esophagitis is due to the fact that patients with GERD are characterized by increased proximal acid refluxes. ${ }^{30}$ In addition, the present study may indicate that neither histological nor endoscopic esophagitis results in a difference in the atypical symptoms.

There are potential limitations of this study that need to be addressed. We did not use high-resolution magnification endoscopy to further characterize the presence of minimal change in GERD patients with normal endoscopy, since this type of esophagitis has been demonstrated to show different physiologic features from ERD. ${ }^{31}$ Due to the fact that the causation between chest symptoms (chest pain and cough) and GERD is unclear, ${ }^{32}$ the true prevalence of these symptoms is somewhat difficult to determine. Our data might not be suitable for a subset of patients with functional heartburn who do not respond well to proton pump inhibitor, since we excluded patients with reflux symptoms unresponsive to acid suppression therapy.

In summary, our data suggest that atypical symptoms are not uncommon in patients with GERD, and its occurrence appears to be equal between patients with NERD and ERD. The presence of these atypical symptoms appears to be more likely to be linked to typical reflux symptoms than endoscopic or pathological results. Therefore, treatment for NERD as well as ERD should achieve the goal of complete improvement in clinical symptoms, and atypical manifestations may also be alleviated by acid suppression therapy. 


\section{References}

1. Vakil N, van Zanten SV, Kahrilas P, Dent J, Jones R; Global Consensus Group. The Montreal definition and classification of gastroesophageal reflux disease: a global evidence-based consensus. Am J Gastroenterol 2006;101:1900-1920.

2. Cho YS, Choi MG, Jeong JJ, et al. Prevalence and clinical spectrum of gastroesophageal reflux: a population-based study in Asan-si, Korea. Am J Gastroenterol 2005;100:747-753.

3. Frye JW, Vaezi MF. Extraesophageal GERD. Gastroenterol Clin North Am 2008;37:845-858, ix.

4. Wu JC, Cheung CM, Wong VW, Sung JJ. Distinct clinical characteristics between patients with nonerosive reflux disease and those with reflux esophagitis. Clin Gastroenterol Hepatol 2007;5:690-695.

5. Fass R, Fennerty MB, Vakil N. Nonerosive reflux disease - current concepts and dilemmas. Am J Gastroenterol 2001;96:303-314.

6. Jaspersen D, Kulig M, Labenz J, et al. Prevalence of extra-oesophageal manifestations in gastro-oesophageal reflux disease: an analysis based on the ProGERD Study. Aliment Pharmacol Ther 2003;17: 1515-1520.

7. Kulig M, Leodolter A, Vieth M, et al. Quality of life in relation to symptoms in patients with gastro-oesophageal reflux disease - an analysis based on the ProGERD initiative. Aliment Pharmacol Ther 2003;18:767-776.

8. Sharma P, Wani S, Romero Y, Johnson D, Hamilton F. Racial and geographic issues in gastroesophageal reflux disease. Am J Gastroenterol 2008;103:2669-2680.

9. Lundell LR, Dent J, Bennett JR, et al. Endoscopic assessment of oesophagitis: clinical and functional correlates and further validation of the Los Angeles classification. Gut 1999;45:172-180.

10. Hongo M. Minimal changes in reflux esophagitis: red ones and white ones. J Gastroenterol 2006;41:95-99.

11. Wright RA, Hurwitz AL. Relationship of hiatal hernia to endoscopically proved reflux esophagitis. Dig Dis Sci 1979;24:311-313.

12. Frierson HF Jr. Histology in the diagnosis of reflux esophagitis. Gastroenterol Clin North Am 1990;19:631-644.

13. Tack J, Talley NJ, Camilleri M, et al. Functional gastroduodenal disorders. Gastroenterology 2006;130:1466-1479.

14. Chen CL, Liu TT, Yi CH. Disease progression in non-erosive reflux disease (NERD): impact of initial esophageal acid exposure. Dis Esophagus 2010;23:613-617.

15. Chen CL, Yi CH, Cook IJ. Differences in oesophageal bolus transit between patients with and without erosive reflux disease. Dig Liver Dis 2008; $40: 348-354$.

16. Lei WY, Liu TT, Yi CH, Chen CL. Disease characteristics in non-erosive reflux disease with and without endoscopically minimal change esophagitis: are they different? Digestion 2012;85:27-32.

17. Klauser AG, Schindlbeck NE, Muller-Lissner SA. Symptoms in gastro-oesophageal reflux disease. Lancet 1990;335:205-208.

18. Fass R. Erosive esophagitis and nonerosive reflux disease (NERD): comparison of epidemiologic, physiologic, and therapeutic characteristics. J Clin Gastroenterol 2007;41:131-137.

19. Mold JW, Reed LE, Davis AB, Allen ML, Decktor DL, Robinson M. Prevalence of gastroesophageal reflux in elderly patients in a primary care setting. Am J Gastroenterol 1991;86:965-970.

20. Raiha I, Hietanen E, Sourander L. Symptoms of gastro-oesophageal reflux disease in elderly people. Age Ageing 1991;20:365-370.

21. Ours TM, Kavuru MS, Schilz RJ, Richter JE. A prospective evaluation of esophageal testing and a double-blind, randomized study of omeprazole in a diagnostic and therapeutic algorithm for chronic cough. Am J Gastroenterol 1999;94:3131-3138.

22. Guillemot F, Ducrotte P, Bueno L. Prevalence of functional gastrointestinal disorders in a population of subjects consulting for gastroesophageal reflux disease in general practice. Gastroenterol Clin Biol 2005;29:243-246.

23. Baber KF, Anderson J, Puzanovova M, Walker LS. Rome II versus Rome III classification of functional gastrointestinal disorders in pediatric chronic abdominal pain. J Pediatr Gastroenterol Nutr 2008; 47:299-302.

24. Verhaeghe J, Jaecques N, Rombouts J, et al. Functional dyspepsia versus other functional gastrointestinal disorders: a practical approach in Belgian general practices. Scand J Gastroenterol 1993; 195(suppl):25-34; discussion 34-25.

25. Lin M, Triadafilopoulos G. Belching: dyspepsia or gastroesophageal reflux disease? Am J Gastroenterol 2003;98:2139-2145.

26. Ismail-Beigi F, Horton PF, Pope CE 2nd. Histological consequences of gastroesophageal reflux in man. Gastroenterology 1970; 58:163-174.

27. Nandurkar S, Talley NJ, Martin CJ, Ng T, Adams S. Esophageal histology does not provide additional useful information over clinical assessment in identifying reflux patients presenting for esophagogastroduodenoscopy. Dig Dis Sci 2000;45:217-224.

28. Dent J. Microscopic esophageal mucosal injury in nonerosive reflux disease. Clin Gastroenterol Hepatol 2007;5:4-16.

29. Vieth M, Kulig M, Leodolter A, et al. Histological effects of esomeprazole therapy on the squamous epithelium of the distal oesophagus. Aliment Pharmacol Ther 2006;23:313-319.

30. Cicala M, Emerenziani S, Caviglia R, et al. Intra-oesophageal distribution and perception of acid reflux in patients with non-erosive gastro-oesophageal reflux disease. Aliment Pharmacol Ther 2003;18: 605-613.

31. Nakamura T, Shirakawa K, Masuyama H, Sugaya H, Hiraishi H, Terano A. Minimal change oesophagitis: a disease with characteristic differences to erosive oesophagitis. Aliment Pharmacol Ther 2005; 21(suppl 2):19-26.

32. Ormseth EJ, Wong RK. Reflux laryngitis: pathophysiology, diagnosis, and management. Am J Gastroenterol 1999;94:2812-2817. 